\author{
Cadernos de \\ ESTUDOS LINGḯSTIICOS - (57.2), Campinas, Jul./Dez. 2015
}

\title{
ELEMENTOS DISCURSIVOS DA GOVERNAMENTALIDADE DO CORPO DAS POPULAÇÕES EM ENUNCIADOS MIDIÁTICOS SOBRE A AIDS, NOS ANOS 1980
}

\author{
HOSTER OLDER SANCHES \\ Universidade Estadual de Maringá (UEM) \\ PEDRO LUIS NAVARRO BARBOSA \\ Universidade Estadual de Maringá (UEM)
}

\begin{abstract}
RESUMO: Em 1987, o jornal Folha de S.Paulo, diário impresso de notícias, fez circular uma vasta produção discursiva cuja temática era a aids. Durante o mês de junho, o jornal apresentou uma sequência de discursos políticos voltados ao crescimento da contaminação do vírus HIV em todo o mundo. Uma análise voltada para essa história de curta duração dá visibilidade à governamentalidade do corpo da população, tema deste artigo. Para tanto, buscou-se, no acervo digitalizado desse periódico, o registro de discursos sobre o acontecimento da aids na segunda metade da década de 1980. A partir da constituição e da descrição desse corpus, pode-se compreender como o governo dos corpos é enunciado e como esse enunciado é materializado em notícias e em reportagens. A fundamentação teórica do trabalho está alicerçada em pressupostos teóricos de Michel Foucault, especialmente no que tange aos estudos sobre enunciado, governo e poder. Observa-se que o Estado deve saber tudo sobre as práticas dessas populações e dos indivíduos, especialmente, as inerentes à sexualidade, que se configuram como objeto, nos termos de Foucault, de um "controle-repressão". A produção de saberes sobre a aids ocorre em meio ao exercício desse poder governamental e da resistência que a ele é feita. Nesse jogo discursivo, ressalta-se uma preocupação em conhecer o estado biológico de cada população, sendo algumas o foco de atuação do poder político, como a população homossexual e a carcerária. Observa-se que a governamentalidade do corpo do indivíduo e das populações é prioridade do Estado em relação à aids; em vista disso, o corpo da população de estrangeiros, de homossexuais e de prisioneiros é mantido sob o olhar clínico e político do Estado e da ciência, a fim de identificá-lo e separá-lo. O Estado, portanto, submete o corpo do portador do vírus HIV a relações de poder/saber e resistência presentes nas tramas sociais.
\end{abstract}

Palavras-chave: discurso; aids; governamentalidade.

ABSTRACT: The newspaper Folha de São Paulo published in 1987 an extensive discursive production on aids. During June the newspaper forwarded a sequence of political discourses on the increasing number of contamination cases by HIV worldwide. An analysis of this short term story provided visibility to the governmentality of the population's body which is the subject of current investigation. The register of discourses on aids during the late 1980s was laid bare in the newspaper's digitalized database. The constitution and description of the above-mentioned corpus brings to the fore the manner the body is announced and how it is materialized in news and in reports. Current research is foregrounded on Foucault's theoretical presuppositions, mainly on his studies on the enunciation, government and power. The State must know all on populations' and individuals' practices, especially those inherent to sexuality, which may be characterized as 'control-repression' in Foucault's terms. 
The production of knowledge on aids occurs within the exercise of government's power and resistance against it. Concern within the discursive interplay is highlighted on the biological state of each population with the focalization of objects, such as homosexuals and jailed people, by the political body. It should be noted that the governmentality of the individual's and the populations' body holds priority in the State vis-à-vis aids epidemic. The body of foreigners, homosexuals and prison populations is kept under the clinical and political surveillance of the State and Science to identify and ostracize it. The state submits the HIV-contaminated body to relationships of power/knowledge and resistance present in social networks.

Keywords: discourse; aids; governmentality.

\section{INTRODUÇÃO}

As discussões realizadas neste texto inserem-se em uma visada discursiva da linguagem, segunda a qual língua e história fornecem ancoragem discursiva para as relações de poder/saber que se projetam sobre os sujeitos, sobre seu corpo e sobre sua sexualidade. Do ponto de vista de uma história serial, como reivindica Foucault (1972), a análise agrupa um conjunto de enunciados cuja condição de existência ocorre a partir de um acontecimento que produziu uma descontinuidade tanto nas relações interpessoais quanto nas políticas públicas: a descoberta da aids, no início dos anos 1980.

$\mathrm{O}$ artigo apresenta resultados parciais de uma pesquisa mais abrangente ${ }^{1}$, que tem como objetivo principal analisar o discurso sobre a aids na década de 1980, no Brasil, em um arquivo composto por textos da mídia impressa.

Para o momento, duas grandes interrogações mobilizam as análises propostas: (a) de que modo o governo do corpo do indivíduo e da população é enunciado em um contexto histórico marcado pelo crescente número de infectados pelo IV?; (b) como esse enunciado se materializa em textos veiculados pelo jornal Folha de S. Paulo?

A descrição das formas de governamentalidade do corpo do sujeito com aids é feita a partir de uma série enunciativa selecionada de sete edições do mês de junho de 1987, do referido veículo de comunicação, cujo tema é a aids e as técnicas de governamentalidade praticadas sobre o corpo das diferentes populações. O jornal Folha de S. Paulo foi escolhido para compor o corpus desta investigação, pelo fato de o diário apresentar acervo digital disponível à pesquisa gratuita na rede mundial de computadores. Ainda com relação ao recorte empírico realizado, o levantamento das matérias produzidas pelo jornal, em 1987, mostrou que, no mês de junho, o assunto em tela ganhou maior visibilidade, em virtude da quantidade de textos relacionados à doença naquele ano.

A série enunciativa que compõe o corpus deste artigo contém sete sequências enunciativas; que falam da temática da aids e apresentam traços do exercício da governamentalidade do sujeito e da população por parte do poder político e também por parte de outros campos, como o religioso. 


\section{CONDIÇÕES DE POSSIBILIDADE}

Estar condenado à fatalidade era o que se produzia discursivamente no período supracitado com relação ao indivíduo portador do vírus HIV: "o inexorável rumo para a fatalidade", (ROSENTHAL. FOLHA, 1987, p. A13). A gravidade da patologia fez com que os governos de diferentes nações passassem a produzir cada vez mais discursos sobre a contaminação, cujos prognósticos, segundo especialistas da época, chegavam a ameaçar o potencial da mão de obra em algumas regiões do globo terrestre. Tais discursos foram produzidos com o objetivo de alertar a população e disseminar medidas preventivas, muitas vezes descabidas para as práticas do século XXI, como, por exemplo, o impedimento de ingressar em um país porque se é portador do HIV. Tais medidas foram adotadas para conter o avanço da contaminação pelo HIV, como se observa nos registros discursivos daquele período.

Um exemplo de medida governamental tomada no ano de 1987 foi a exigência do teste antiaids para imigrantes nos Estados Unidos. A aids não ameaçava somente o indivíduo que a contraía: a doença passou a ameaçar toda a cadeia produtiva dos Estados, já que o sujeito contaminado tinha sua capacidade produtiva restringida ou, na maioria dos casos, anulada devido à gravidade da síndrome que se espalhava entre as populações. Com tal efeito, a doença passou não só a ameaçar o corpo individual, mas o corpo social, o qual é denominado por Foucault (1988) de "população".

\section{FUNDAMENTAÇÃO TEÓRICA}

\subsection{Do exercício do poder: o governo das populações}

A fim de conceituar o termo "população", Michel Foucault remonta ao século XVIII, quando os governos das nações livres passaram a cuidar do corpo formado pela pluralidade dos indivíduos, corpo esse denominado população, pelo autor. A sociedade constitutiva do Estado, segundo ele, é composta por diferentes populações: de trabalhadores, de empresários, de educadores, de médicos, de professores etc. Dessa forma, as informações acerca dessas populações passaram a ser fundamentais para o governo político dos Estados, ou seja:

Os governos percebem que não têm que lidar simplesmente com sujeitos, nem mesmo com um "povo", porém com uma "população", com seus fenômenos específicos e suas variáveis próprias: natalidade, morbidade, esperança de vida, fecundidade, estado de saúde, incidência das doenças, forma de alimentação e habitat, (FOUCAULT, 1988, p. 31).

As populações, então, são o foco do governo do Estado. Porém, aceitando o pensamento foucaultiano, toma-se por governo um posicionamento conceitual diverso daquele que remete a um governo centralizador, exercido a partir de um ponto. Ao contrário, o governo não é exercido somente por um eleito ou por um déspota: o governo é praticado pelos sujeitos em relações sociais, como o governo 
exercido pelo professor sobre o aluno ou o governo do médico sobre o paciente. Segundo Foucault (2012, p. 411), “o governante, as pessoas que governam, a prática de governo são, por um lado, práticas múltiplas, à medida que muita gente pode governar: o pai de família, o superior do convento (...)”. Há, portanto, o governo político exercido sobre as populações e o governo entre sujeitos, nas malhas das relações em sociedade.

Com isso, a população passou a ser o foco do governo dos Estados. Conhecer cada vez mais a população e os seus fenômenos passou a ser uma preocupação constante das diferentes nações, fazendo surgir mais informações acerca das características cada vez mais específicas das diferentes populações. As práticas discursivas e não discursivas realizadas por elas serão aferidas e regidas por uma governamentalidade. De acordo com Foucault (2012, p. 426), “a constituição de um saber de governo é absolutamente indissociável da constituição de um saber sobre todos os processos referentes à população em sentido lato, daquilo que chamamos precisamente de "economia"'. Portanto, todo saber de governo está associado a um saber de economia sobre a população. Cotejando tais saberes, eles formarão os pilares do saber das técnicas de governo das populações. Os dados da economia da população tornaram-se objeto das técnicas de governo.

Ao analisar tais técnicas de governo das populações, apresenta importância singular compreender, antecipadamente, alguns conceitos importantes à análise das sequências enunciativas apresentadas no texto. A seguir, são expostas as ferramentas foucaultianas recorridas para a análise do discurso.

\subsection{Acontecimento, série e enunciado}

Para a elaboração do corpus desta investigação, procurou-se realizar um recorte, no discurso sobre a aids, que tomasse como ponto de partida não a origem desse discurso, mas sim um dos momentos em que, sobre o tema, passou-se a produzir cada vez mais discursos, os quais apresentam determinados objetos, que persistem em diferentes discursos, repetem-se em diferentes formações discursivas, como a política, a jurídica, a médica e a pedagógica, todos eles voltados para o corpo do indivíduo e o corpo da população ameaçada pelo vírus HIV.

Conforme anunciado anteriormente, considera-se a descoberta da aids como um acontecimento de ordem social, econômica e política e por corolário, os discursos que trabalharam, à época, e continuam trabalhando esse acontecimento também devem ser assim concebidos.

Tomar como ponto de partida a concepção de discurso como acontecimento implica levar em conta o que assevera Foucault (1972) sobre as "regras de formação" discursivas e sobre a noção de "arquivo". A aids como referencial dos enunciados aqui analisados emerge como objeto discursivo, em meio a um campo associativo que abarca saberes de ordem médica, jurídica, religiosa e familiar, para citar alguns. É essa teia discursiva que dá condições para falar sobre a doença de um modo e não de outro, é ela, portanto, que responde pelas condições de enunciabilidade da doença e do corpo infectado, ou seja, pelo arquivo do que se disse sobre tal epidemia, nos anos 1980. Tendo em vista, contudo, que o arquivo, 
segundo Foucault, é indescritível em sua totalidade, os enunciados analisados nestas páginas devem ser vistos como um recorte dessa produção discursiva.

Isso coloca, de saída, um problema de ordem metodológica à pesquisa, que é o de estabelecer as correlações entre os enunciados-acontecimento e as regularidades que os mantêm sob uma mesma "regra de formação" discursiva (FOUCAULT, 1972).

De acordo com Foucault,

Um enunciado é sempre um acontecimento que nem a língua nem o sentido podem esgotar inteiramente. Trata-se de um acontecimento estranho, por certo: inicialmente porque está ligado, de um lado a um gesto de escrita ou à articulação de uma palavra (...) porque é o único como todo acontecimento, mas está aberto à repetição, à transformação, à reativação; finalmente, porque está ligado não apenas a situações que provocam, e a consequências por ele ocasionadas, mas, ao mesmo tempo, e segundo uma modalidade inteiramente diferente, a enunciados que o precedem e o seguem, (FOUCAULT, 1972, p.34).

Para esse autor, a história nova problematiza a causalidade histórica, ao privilegiar as séries, os recortes, os limites, os desníveis, os deslocamentos. Sua tarefa, portanto, é:

\begin{abstract}
determinar que forma de relação pode ser legitimamente descrita entre essas diferentes séries, que sistema vertical elas são suscetíveis de formar, qual é, de umas para outras, o jogo das correlações e das dominâncias; de que efeito podem ser os deslocamentos, as temporalidades diferentes, as diversas permanências; em que conjuntos distintos certos elementos podem figurar simultaneamente (FOUCAULT, 1972, p.18).
\end{abstract}

Foucault rejeita o continuísmo presente na história tradicional, por considerálo um refúgio do antropocentrismo, um correlato indispensável ao sujeito, concebido como origem de todo o devir e senhor consciente de sua história. Nessa história contínua, "o tempo é aí concebido em termos de totalização e as revoluções jamais passam aí de tomadas de consciência" (FOUCAULT, 1972, p.21). A tarefa desse tipo de história resume-se, desse modo, a construir uma história global, explicativa e dotada de sentido, capaz de restituir a continuidade complexa do devir histórico.

A finalidade do filósofo, entretanto, é outra. Trata-se de perseguir algo como uma história geral, constituída de múltiplos centros de estruturação e de dispersão, de uma pluralidade de sentidos. Desse modo, contra a concepção de história que se desenvolveria em uma continuidade linear e simples, Foucault, fundamentado em Bachelard, Canguilhem e Nietzsche, apresenta uma genealogia cujo motor é a descontinuidade.

Nas análises que Foucault empreende sobre as condições de emergência dos saberes e dos objetos por eles instituídos, a noção de descontinuidade figura como um conceito operatório com o qual o autor faz surgir aos olhos dos historiadores do seu tempo uma história capaz de colocar em ação um "estruturalismo historicizado", por não estar fechada em torno de um centro, mas, sim, definida como espaço de uma dispersão.

Como bem salienta Dosse, para Foucault importa 
[...] abrir as estruturas para descontinuidades temporais, para as mudanças que regulam os deslocamentos num jogo incessante das práticas discursivas. A desconstrução da disciplina histórica $[. .$.$] passa pela renúncia à busca de continuidades e às tentativas de síntese entre os$ elementos heterogêneos da realidade (DOSSE, 2001, p. 214-15).

O relativismo histórico que emerge das análises sobre as condições de possibilidade e de emergência dos saberes leva à conclusão de que não há verdade para ser buscada nas diversas etapas constitutivas do saber, mas sim discursos historicamente detectáveis, que constroem verdades e possibilitam o exercício do poder.

O método do qual se falava antes consiste em interpretar os documentos existentes e reformulá-los para, então, definir um domínio imenso que comporta o conjunto de todos os enunciados efetivamente falados ou escritos em sua dispersão de acontecimentos e na instância própria a cada um.

Outra questão de método que se coloca, quando se realiza uma pesquisa de caráter discursivo, nos termos expostos aqui, diz respeito à elaboração da série que comporá o objeto de investigação:

o problema é constituir séries: definir para cada uma seus elementos, fixar-lhes os limites, descobrir o tipo de relações que lhe é específico, formular-lhes a lei e, além disso, descrever as relações entre as diferentes séries, para constituir, assim, série de séries, ou "quadros": daí a multiplicação dos estratos, seu desligamento, a especificidade do tempo e das cronologias que lhes são próprias (...) daí a possibilidade de fazer com que apareçam séries com limites amplos, constituídas de acontecimentos raros ou de acontecimentos repetitivos, (FOUCAULT, 1972, p. 9).

A série, portanto, corresponde ao corpus elaborado a partir de um questionamento que determina e direciona a análise empreendida. Tendo em vista a finalidade deste artigo, tal questionamento divide-se em dois: (a) de que modo o governo do corpo do indivíduo e da população é enunciado em um contexto histórico marcado pelo crescente número de infectados pelo HIV?; (b) como esse enunciado se materializa em textos veiculados pelo jornal Folha de S. Paulo?

No acervo do referido jornal, disponível no endereço eletrônico http://acervo. folha.com.br/fsp, o ano de 1987 é marcado por uma intensa produção de discursos sobre a aids, materializada em matérias jornalísticas ou em notícias diárias sobre o assunto. Tal fato impeliu à realização de um recorte temporal, que foi norteado pelo estabelecimento de uma série enunciativa destacada do quadro discursivo relativo ao discurso sobre a aids. Para tanto, foi necessário observar alguns importantes pontos da série, tais como os expostos na citação anterior.

Os enunciados que compõem a série formulada mantêm certa regularidade quanto a determinados objetos, uma permanência que acaba por estabelecer uma relação entre esses enunciados. Certos pontos de intersecção entre os enunciados da série podem ser identificados: a governamentalidade praticada sobre o corpo da população; os movimentos articulatórios do poder político que se ocupada da vida, do biológico da população, configurando-se, assim, em uma biopolítica. Todas essas técnicas de poder encontram-se, na série, voltadas à realidade ameaçada pela aids. 
(adernos de ESTUDOS LINGüísTICOS (57.2) - Jul./Dez. 2015

Uma das ferramentas fundamentais para esta investigação é o enunciado. Sendo assim, faz-se necessário fundamentar esse conceito. Entende-se que o enunciado é um acontecimento de ordem discursiva, seja essa ordem manifestada materialmente por meio da expressão verbal oral ou escrita. Por se tratar de um acontecimento, Foucault afirma que o enunciado é um acontecimento cuja origem estaria sempre em uma relação mais profunda e secreta, impossibilitando, ao analista ou ao autor de uma obra, por exemplo, determinar o ponto inicial, a origem de determinado enunciado.

É instaurada, em uma perspectiva discursiva, uma rede em que se encontra o enunciado cujas fronteiras se estendem aos enunciados possíveis em determinado momento, ou seja, o que se poderia dizer em determinado momento e em determinadas localidades; enunciados que estão no verdadeiro da época, enfim, considerar a positividade dos enunciados.

Os enunciados da série mantêm relações com outros enunciados ditos e não ditos sobre a aids naquele período e nos que se seguiriam. Podem formar séries enunciativas que, muitas vezes, advêm de domínios distintos, mas que, na materialidade do discurso jornalístico, dialogam e se limitam. Em termos arqueológicos, enunciado é "uma função que cruza um domínio de estruturas e de unidades possíveis e que faz com que apareçam, com conteúdos concretos, no tempo e no espaço", (FOUCAULT, 2012, p. 105).

Destarte, os enunciados são de ordem técnica, provenientes do campo da medicina (da infectologia e virologia, especificamente), e de ordem políticopartidária; eles se entrecruzam no emaranhado das possíveis enunciações sobre o HIV. Em vista disso, assumem a característica de função que atravessa as estruturas dessas ciências, formando um conjunto, já que os enunciados do recorte aqui operado gravitam em torno de um mesmo referencial discursivo, qual seja, o indivíduo com comportamento considerado de risco de infecção pela aids, como os homossexuais, usuários de drogas injetáveis, indivíduos que mantiveram ou mantêm relações sexuais com diversos parceiros e com os imigrantes.

Essa condição de produção do discurso possibilitou que um vasto conjunto de enunciados constituísse um arquivo, que passou a reger o modo de falar da doença, de identificar, de classificar, de separar e de aprisionar os corpos doentes ou suspeitos de infecção, a fim de conter a pandemia, pois as previsões eram desastrosas, principalmente nos países africanos.

Medidas judiciais exigindo o teste de detecção do vírus HIV passaram a ser impetradas em diversos países. Os enunciados multiplicam-se: (1) "EUA tornam obrigatório teste anti-Aids para imigrantes", (Folha, 04/06/1987, p. A18); (2) "No Carandiru, confinamento de aidéticos provoca rebelião", (Folha, 06/06/1987, p. A11); (03) "Paciente é discriminado pela sociedade e pelos médicos", (Folha, 03/06/1987, p. A 13); (04) "URSS adota a medida para estudantes estrangeiros", (Folha, 10/06/1987, p. A15); ou ainda, (05) "Aceitar uma pessoa independentemente de sua preferência sexual - e que sabidamente tem ou teve múltiplos relacionamentos sexuais com parceiros variados - é uma proposta no mínimo incômoda para o nosso tipo de sociedade", (Folha, 03/06/1987, p. A13). 
As análises sinalizam que o discurso sobre a aids apresenta a relação comum que reúne os enunciados constitutivos de uma mesma formação discursiva, já que o conjunto de objetos persiste em diferentes discursos, como, por exemplo, o indivíduo estrangeiro, o paciente portador do vírus da aids e o comportamento sexual das pessoas. Anuindo às palavras de Foucault (1972, p. 42), é preciso

caracterizar e individualizar a coexistência desses enunciados dispersos e heterogêneos; o sistema que rege sua repartição, como se apoiam uns nos outros, a maneira pela qual se supõem ou se excluem, a transformação que sofrem, o jogo de seu revezamento, de sua posição e da sua substituição.

Entretanto, seguindo os passos de Foucault, a unidade dessa produção discursiva não está no seu reagrupamento em torno de tais objetos, não se encontra também na forma e no tipo de encadeamento dos enunciados ou no sistema dos conceitos permanentes e coerentes, muito menos na identidade e persistência de temas. Contudo, é possível encontrar nessa dispersão uma regularidade, que se verifica no acontecimento a que os enunciados se reportam e na posição que o sujeito ocupa no texto como jornalista-observador da "realidade".

\section{ANÁLISE}

Como o foco desta investigação recai é a governamentalidade exercida sobre a população envolta com a temática da aids, é importante destacar a tríplice composição da governamentalidade. Foucault (2012, p. 429) define o conceito de governamentalidade a partir de três considerações sobre o termo:

1. O conjunto constituído pelas instituições, procedimentos, análises e reflexões, cálculos e táticas que permitem exercer esta forma bastante específica e complexa de poder, que tem por alvo a população, por forma principal de saber a economia política e por instrumentos técnicos essenciais os dispositivos de segurança.

2. A tendência que em todo o Ocidente conduziu incessantemente, durante muito tempo, à preeminência deste tipo de poder, que se pode chamar de governo, sobre todos os outros - soberania, disciplina etc. - e levou ao desenvolvimento de uma série de aparelhos específicos de governo e de um conjunto de saberes.

3. O resultado do processo através do qual o Estado de justiça da Idade Média, que se tornou nos séculos XV e XVI Estado administrativo, foi pouco a pouco governamentalizado.

Atentando para as medidas instauradas pelos governos dos Estados, o recorte efetuado no material midiático obedeceu ao seguinte critério: os enunciados constituintes da série apresentam práticas voltadas à governamentalidade da população, o governo dos corpos doentes ou com suspeitas de infecção.

A governamentalidade dessa população manifesta-se nas relações de poder instauradas na sociedade, sendo que, como visto, a governamentalidade está diluída 148 
(adernos de ESTUDOS LINGḯlsTICOS (57.2) - Jul./Dez. 2015

nas relações sociais cotidianas da população. Ainda sobre o exercício desse tipo de poder, Foucault (2010, p. 225) acrescenta que se trata de "um campo estratégico de relações de poder, no sentido mais amplo do termo, e não meramente político, entendida, pois, como um campo estratégico de relações de poder no que elas têm de móvel, transformável, reversível".

\subsection{Discurso sobre a Aids: o corpo da população carcerária}

Com a ameaça da aids, medidas governamentais passaram a ser adotadas de forma a controlar a infecção da doença, como se pode constatar no excerto abaixo:

(1): "No Carandiru, confinamento de aidéticos provoca rebelião". "A situação exige uma adaptação e uma reformulação de valores. Implicações de ordem moral decorrem da característica toda peculiar da infecção, que resulta, em grande parcela dos casos, da promiscuidade sexual. 'Quanto maior o número de parceiros, maior o risco de se entrar em contato com o vírus",, (ROSENTHAL, Caio. Folha,03/06/1987, p. A13).

Nesse trecho, é notável a preocupação daqueles que se encontravam em regime de restrição de liberdade. A liberdade de relacionamento entre os presos passa a ser motivo de preocupação dos governantes do presídio Carandiru, localizado na zona Norte da capital paulista. O presídio, hoje desativado, era constituído por alas masculinas e por alas femininas.

Devido ao grande número de detentos, a manifestação do vírus HIV no presídio exigiu medidas dos dirigentes. Como observado no enunciado acima, os corpos devem ser separados e mantidos em confinamento. Tal medida é decorrente do caráter promíscuo do ambiente, considerado causa da contaminação, ou seja, os enclausurados portadores do vírus devem ser punidos pela prática sexual, considerada difusa, que mantinham na sociedade. Os detentos portadores do vírus HIV, mesmo segregados da sociedade pelo confinamento no presídio, mantêm contato com outros detentos que não são portadores, oferecendo possíveis riscos à população carcerária. Com isso, a preocupação estava em interditar as práticas daqueles que já se encontravam segregados. Em termos discursivos, esse enunciado materializa os efeitos de uma biopolítica que se vale de biopoderes exercidos a fim de controlar o corpo dessa população carcerária.

Assim, o sujeito que enuncia o faz a partir de uma ordem discursiva que avalia a aids a partir de determinadas características de caráter imoral da contaminação, avaliação essa que se apresenta na seguinte escolha lexical: valores, ordem moral e promiscuidade.

Em virtude dessas condições de produção discursivas, o enunciado formulado encontra-se investido de ordem moral diversa da que se acredita que o portador da aids pratica. A moral praticada pelos sujeitos na sociedade, segundo enunciado em questão, apresenta valores distintos da ordem moral supostamente praticada pelos sujeitos que se expunham às condições de contaminação. A possibilidade histórica do discurso permite ao sujeito da enunciação propor a reformulação dos valores 
na sociedade, fato que aponta para um possível desvio dos valores praticados por aqueles que contraíram a aids. Tais valores são, pois, objeto da prática discursiva da governamentalidade que se ocupa mais das práticas morais dos sujeitos do que do combate à doença no organismo humano.

Nessa primeira sequência, destaca-se o emprego dos itens lexicais "valores", "ordem moral" e "promiscuidade" como valores atrelados à prática de poder exercida pela governamentalidade. O sujeito autorizado a falar sobre a doença questiona exclusivamente as práticas não discursivas entre sujeitos que se davam a certas práticas sexuais tidas por livres. Logo, a prática sexual mostra-se o alvo do exercício do governo sobre o outro, distanciando-se de indagações científicas que poderiam ser levadas a laboratórios capazes de desenvolver pesquisas a fim de tratar os contaminados pelo HIV. A governamentalidade, por meio da biopolítica, investe-se de biopoder para regular as condutas dos sujeitos em suas práticas sociais. Fernandes $(2012$, p.52) recorre aos preceitos foucaultianos para confirmar que "o poder organiza-se em torno da vida; há, portanto, uma biopolítica investida de biopoderes".

(2): EUA já começam a aplicar teste anti-Aids em presos. "O ministro da Justiça dos EUA, Edwin Meese, anunciou ontem um plano para iniciar a aplicação de testes obrigatórios anti-Aids em imigrantes e prisioneiros federais (...) A maior novidade do discurso de Meese foi considerar 'imprópria' a concessão de liberdade condicional a prisioneiros que, embora tenham demonstrado bom comportamento, portem o vírus da Aids", (FOLHA, 10/06/1987).

A sequência (2), relativa à população carcerária, retoma as relações de poder. No trecho “'(...) considerar 'imprópria' a concessão de liberdade condicional a prisioneiros que, embora tenham mostrado bom comportamento, portem o vírus da Aids", nota-se o jogo das relações de poder. Tal relação possibilita afirmar que a biopolítica suplanta outra forma de poder que é o poder jurídico, pois, se o sujeito condenado a cumprir pena em regime fechado apresentar bom comportamento, tem direito, garantido pela Constituição norteamericana, à progressão da pena, ou seja, a ter a pena reduzida conforme suas condutas dentro da instituição penal. De acordo com Foucault (1997, p. 89), a prática dessa biopolítica é compreendida como

a maneira pela qual se tentou, desde o século XVIII, racionalizar os problemas propostos à prática governamental, pelos fenômenos próprios a um conjunto de seres vivos constituídos em população: saúde, higiene, natalidade, raça...

Dessa forma, a biopolítica, exercendo um biopoder sobre os corpos, ocupa-se não só da população carcerária como também de cada um dos corpos que constitui essa população. Há a necessidade de manter tais corpos contaminados presos, separados, controlados, já que constituem uma ameaça à sociedade livre, a qual se encontra fora dos muros do presídio e é tida como saudável. 
As condições externas de produção discursiva operam sobre os discursos de forma a levar o ministro da Justiça norteamericano a considerar a liberdade condicional dos prisioneiros com o vírus HIV inadequada, embora ele, entre outras atribuições inerentes ao cargo, deve zelar pela justiça naquela sociedade. Portanto, libertar, mesmo que condicionalmente, o sujeito portador da aids é uma afronta à justiça. Tenta-se prender a doença atrás das grades, como já se fez com o louco, a partir do século XVIII.

\subsection{Discurso sobre a Aids: a população estrangeira}

O exercício desse tipo de governo sobre o corpo contaminado da população carcerária expõe, portanto, seu funcionamento discursivo, que se apresenta na forma de processos de segregação. A separação e a rejeição são analisadas por Foucault (1995) como dois elementos de um mesmo princípio, o da exclusão. Numa comparação livre, pode-se aproximar a oposição entre corpo saudável e corpo contaminado com aquela feita por esse autor, entre a razão e a loucura. Desde a Idade Média,

louco é aquele cujo discurso não pode circular como o dos outros: pode ocorrer que sua palavra seja considerada nula e não seja acolhida, não tendo verdade, nem importância, não podendo testemunhar na justiça, não podendo autenticar um ato, ou um contrato... É curioso constatar que durante séculos na Europa a palavra do louco não era ouvida, ou então, se era ouvida, era escutada como uma palavra de verdade (FOUCAULT, 1995, p. 10-11).

A palavra do louco ou era rejeitada, tão logo pronunciada, ou se creditava a ela uma razão ingênua, mística, astuciosa ou superior. De uma forma ou de outra, pesava a exclusão, seja por meio da rejeição ou da separação. Nessa comparação livre, o que conta é o aspecto de anormalidade que pesa tanto sobre o louco quanto sobre o aidético.

Foucault (1998) observa que a medicina categoriza em quadros de sinais e sintomas tudo aquilo que se diferencia no ser humano e não pode ser classificado como normal. Nesse panorama, o discurso médico, no século XVIII, com o intuito de dar uma ordem ao caos em que encontrava a saúde pública, põe em funcionamento todo um aparato técnico de observação, de descrição e de classificação das doenças. Tem-se assim o nascimento de uma arqueologia do olhar clínico que se volta para a diferença, legitimado que está para estabelecer a distinção entre os estados de normalidade e de anormalidade, sejam eles de ordem psíquica ou de natureza imunológica.

Ainda buscando respaldo no texto de $A$ ordem do discurso, concluise que tanto a medicina preventiva quanto a biopolítica inventam o aidético, transformando-o em objeto de saber. Como corolário, conceitos como os de "peste gay", por exemplo, são produzidos pelas práticas discursivas de determinada época, no caso, a década de 1980, como em: “o motorista de táxi José Antônio da Graça, 44, diz que 'se eu pegar essa peste gay, ninguém vai acreditar que foi no dentista, vai?'”, (Folha de S. Paulo, 04/08/1985, p. 33). Tendo em conta a relação poder-saber, o exercício da governamentalidade tem a capacidade de produzir o 
real, ou seja, o que é visível (o corpo do sujeito contaminado pelo vírus) e o que é dizível (os enunciados que falam sobre esse sujeito).

As populações carcerárias brasileiras e norte-americanas passam a ser objeto do poder político exercido sobre os corpos dos indivíduos e da população, tendo como foco a vida da população. A população de estrangeiros também não escapa a esse biopoder. A seguir, destacam-se sequências enunciativas nas quais o objeto do biopoder é a população estrangeira, o estranho ao corpo da população que o recebe.

(3): URSS adota a medida para estudantes estrangeiros. "Os estudantes estrangeiros e os interessados em estudar na União Soviética estão tendo que se submeter a teste anti-Aids”, (FOLHA, 10/06/1987, A 15).

(4): EUA tornam obrigatório teste anti-Aids para imigrantes. "O Senado dos Estados Unidos aprovou por unanimidade (96 votos) uma lei exigindo que os imigrantes sejam submetidos a teste para verificação de Aids. Caso o teste resulte positivo, o imigrante terá vetada sua entrada no país ou, se for o caso, poderá ser expulso”, (FOLHA, 4/06/1987, A18).

Na terceira sequência, o enunciado é atravessado pelo campo discursivo acadêmico. A URSS exige o teste antiaids de acadêmicos ou não que desejam estudar no país. Essa decisão, que parte do poder político, busca no biopoder alternativas para o controle da doença. Dessa forma, o discurso sobre a aids desloca-se do foco anterior, constituído por grupos de homossexuais, usuários de drogas injetáveis e os sujeitos em regime de prisão, para o grupo de sujeitos que vêm de fora da sociedade em questão.

Está presente a busca de governar os corpos estranhos à sociedade dos Estados. Destarte, o poder atua sobre os sujeitos a fim de conhecer a conduta de cada um. Entende-se por conduta o "o ato de 'conduzir' os outros e a maneira de se comportar num campo mais aberto de possibilidade" (FOUCAULT, 2012, p. 57). $\mathrm{O}$ enunciado dá visibilidade à busca de governar aqueles que se encontram em um campo maior de possibilidade. Tal campo de possibilidade pode ser visto como as diferentes culturas e populações de onde os estudantes estrangeiros provêm. Visase, pois, não só governar o corpo da população desse Estado, mas também aquilo que o transcende e o perpassa. O corpo apresenta-se como objeto daquilo que se deve conhecer e governar.

A quarta sequência enfatiza tanto o controle que incide sobre a vida da população quanto o exercício dispendioso ao qual o Estado se dispõe. Conforme enunciado nesse recorte, a ordem discursiva, advinda do acontecimento "descoberta do vírus da aids", impõe-se sobre essa população, discriminando os sujeitos contaminados pelo vírus e que não estão. $\mathrm{O}$ funcionamento dessa ordem pesa como lei que separa e segrega os corpos, por meio de medidas biopolíticas, as quais resultam em uma relação de biopoder. Portanto, os Estados procuram gerir o corpo de sua população, ao identificar e separar os corpos contaminados de populações estrangeiras. 
(5): Teste obrigatório é criticado por hispânico. "A obrigatoriedade de testes anti-Aids em imigrantes, prisioneiros federais e viciados em drogas intravenosas sob tratamento aprovada terça-feira pelo Senado dos Estados Unidos, que ainda depende da aprovação da Câmara dos deputados, está provocando críticas por parte de organizações de hispânicos, de aidéticos $e$ de organizações de defesa civil dos EUA", (ARBEX, Caio. Folha, 05/06/1987, A. 11).

(6): Nos Estados Unidos, só mandados judiciais podem garantir a obrigatoriedade do teste. "Religiosos de várias estirpes também prejudicam o combate à Aids. Parece uma mínima precaução que se faça uma campanha pública pelo uso de preservativos no ato sexual. Está provado que o sexo anal é a grande fonte de Aids. Mas a Igreja Católica e outras menores se opõem veementemente à divulgação pública em televisões (...) Os religiosos querem que as pessoas deixem de fazer sexo fora do matrimônio e que não seja para a procriação", (FOLHA, 2/06/1987, A. 13).

\subsection{Governamentalidade e outros campos de saber}

As sequências (5) e (6) apresentam a temática da aids vista de campos discursivos diferentes. O governo da população apresenta um discurso atravessado por diferentes poderes, portanto, por diferentes saberes. Materializam-se os saberes médico, religioso e político, vinculados ao poder que se exerce nesse contexto histórico.

Considerando que toda relação de poder é afetada por focos de resistência, o enunciado (5) significa que o poder político encontra resistência de certas populações no território norte-americano, as quais são foco das medidas propostas pelo governo político. Assim, a população composta por estrangeiros, hispânicos, detentos e usuários de drogas injetáveis não aceita se submeter ao teste proposto pelo Estado para detecção do vírus da aids.

Segundo a sequência (6), o poder político do Estado esbarra no campo discursivo religioso, o qual proíbe métodos anticoncepcionais, portanto, o uso de preservativo, método mais eficaz de combate à transmissão do vírus pela prática sexual. Esse campo encontra resistência no científico, também presente no enunciado, pois é esse poder, investido de conhecimento, que se contrapõe ao discurso religioso. Além disso, a prática do sexo livre é controlada pelo poder político, o qual se vale de uma biopolítica reguladora das práticas do cuidado de si. O desejo do corpo pelo próprio corpo deve ser controlado a fim de evitar práticas sexuais de alto risco, como a prática do sexo anal, aludindo, principalmente, às práticas homossexuais.

(7): Nova York tem plano contra a doença. “(...) Em Nova York e Londres, emissoras de rádio e TV censuraram pela primeira vez uma música por causa da Aids. A música, intitulada 'I want your sex', faz parte da trilha sonora do 
filme 'Beverly Hills Copy Cop 2', e foi censurada pela 'BBC' de Londres e por rádios nova-iorquinas sob a alegação de que seu conteúdo defende explicitamente a prática sexual livre", (FOLHA, 04/06/1987. A. 18).

Além das regulações impostas pelo Estado, das interdições do discurso religioso, o discurso sobre a sexualidade dos sujeitos encontra resistência nas relações de mercado. Fernandes (2012, p. 59) retoma Foucault para ratificar que corpo e sujeito devem ser entendidos como conceitos distintos: "o sujeito passa a ser considerado como uma função, ou como uma posição a ser ocupada nos discursos".

Ao interditar a música "I want your sex", as emissoras radiofônicas e televisivas londrinas, propagadoras de discursos de diferentes campos do saber, censuram a expressão da liberdade sexual devido à ameaça da aids. A doença passa a produzir interdições não somente nas práticas do sujeito consigo mesmo, mas com seu corpo. O saber sobre essa doença passa, também, a observar e a interditar determinados comportamentos culturais das diversas populações afetadas pelas interdições.

\section{CONSIDERAÇÕES FINAIS}

Analisando a série de enunciados acima, o exercício da governamentalidade sobre populações específicas fica evidente. Embora a aids seja uma ameaça à vida de qualquer ser humano, o exercício do governo restringe sua atuação sobre o corpo de determinadas populações.

O biopoder, exercido, principalmente, pela biopolítica, ocupou-se dos corpos inseridos em comunidades de maior ocorrência dos casos de aids. Busca-se o governo das populações estrangeiras, pois o corpo estranho à comunidade que o recebe torna-se uma potencial ameaça. Portanto, o corpo dessa população deve passar por exames que atestem sua saúde. Caso contrário, se o corpo estrangeiro apresenta contaminação pelo HIV, ele é interditado e impedido de ingressar (nesse caso) em território norteamericano.

O controle sobre os corpos mostrou-se acentuado quando a questão foi o corpo da população das prisões. O corpo do sujeito é enclausurado e impedido de ganhar a liberdade, mesmo que o poder judicial o tivesse libertado. A segregação do corpo tem efeitos na constituição do indivíduo em sujeito, pois essa violência interfere nos processos de subjetivação: o aidético é submetido, nas relações de poder, a medidas biopolíticas mais austeras.

\section{REFERÊNCIAS BIBLIGRÁFICAS}

DOSSE, F. A história à prova do tempo: da história em migalhas ao resgate do sentido. Trad. Ivone C. Beneditti. São Paulo: Editora da UNESP, 2001.

FERNANDES, C. A. Discurso e sujeito em Michel Foucault. Editora Intermeios. São Paulo, 2012. 
FOUCAULT, M. A Arqueologia do Saber. Tradução: Luiz Felipe Baeta Neves. $8^{\mathrm{a}}$ edição. Editora: Forense Universitária. Rio de Janeiro, 1972.

FOUCAULT, M. História da sexualidade I: A vontade de saber. Tradução. Maria Tereza da Costa Albuquerque e J. A. Guilhon Albuquerque. 21 ${ }^{\text {a }}$ reimpressão. Editora Graal. Rio de Janeiro, 1988.

FOUCAUlT, M. A ordem do discurso. Trad. Adalberto de O. Souza. Série Apontamentos no 29. Maringá: Universidade Estadual de Maringá, 1995.

FOUCAULT, M. O Nascimento da Clínica. Tradução Roberto Machado. 5 ed. Rio de Janeiro: Forense Universitária, 1998.

FOUCAULT, M. A hermenêutica do sujeito. 3a edição. Tradução: Márcio Alves da Fonseca. Editora WMF Martins Fontes. São Paulo, 2010.

FOUCAULT, M. Microfisica do poder. 25ª edição. Editora Graal. São Paulo, 2012.

http://acervo.folha.com.br/fsp. 